\title{
Bibliometrics of Vietnam Publications in the Science Citation Index: general trends and comparison with other tropical countries
}

\author{
Nguyễn Thị Nha Trang ${ }^{1}$, Julián Monge-Nájera² \& Yuh-Shan $\mathrm{Ho}^{3 *}$ \\ 1. Department of Biotechnology, College of Health Science, Asia University, No. 500 Lioufeng Road, Wufeng, Taichung \\ 41354, Taiwan; nhatrangnguyen113@gmail.com \\ 2. Laboratorio de Ecología Urbana, Vicerrectoría de Investigación, Universidad Estatal a Distancia, 2050 San José, Costa \\ Rica; julianmonge@gmail.com \\ 3. Trend Research Centre, Asia University, No. 500 Lioufeng Road, Wufeng, Taichung 41354, Taiwan; \\ ysho@asia.edu.tw \\ * Correspondence
}

Received 19-IV-2020. Corrected 06-VIII-2020. Accepted 25-VIII-2020.

\begin{abstract}
Introduction: The economy of Vietnam, a highly populated tropical country with a per capita gross domestic product of $\$ 8000$, is growing rapidly, but there are few recent studies of general scope about its scientific productivity and how it compares with other tropical countries. Objective: To identify trends in Vietnamese science and compare them with trends in other tropical countries. Methods: We extracted data about scientific papers, in all disciplines that had Vietnam as country in the Science Citation Index Expanded for the period 1991 to 2018, focusing on type of publication, language, subject, authorship, collaboration, and citations. Results: Vietnam publishes more document types than other tropical countries, and those in this particular database are mostly in English, albeit most Vietnamese science is published in Vietnamese and not covered by the index. The primary categories were multidisciplinary materials science, mathematics, and applied mathematics. Most collaboration was done with the USA, Japan, South Korea, and France. A large number of articles were published by the Vietnam Academy of Science and Technology, and the most frequent foreign collaboration was with the University of Oxford. Conclusion: the tropical countries of Latin America, Africa, and Asia studied in our project have some similarities but also crucial differences. Science is developing rapidly in Vietnam and the production of articles in Vietnamese, which represent the vast majority of research in the country but is not included in this database, should also be studied.
\end{abstract}

Key words: scientific productivity; scientific collaboration; Asia region; tropical science.

Trang, N.T.N., Monge-Nájera, J., \& Ho, Y.S. (2020). Bibliometrics of Vietnam Publications in the Science Citation Index: general trends and comparison with other tropical countries. Revista de Biología Tropical, 68(4), 1221-1230.

In the last decade, publication performances in tropical countries has received much attention. A series studies were presented for Latin America including Costa Rica (MongeNájera \& Ho, 2012), Panama (Monge-Nájera \& Ho, 2015), Nicaragua (Monge-Nájera \& Ho, 2017a), Honduras (Monge-Nájera \& Ho, 2017b), El Salvador (Monge-Nájera \& Ho, 2017c), Guatemala (Monge-Nájera \& Ho,
2018), and Ecuador (Calahorrano, MongeNájera, Wang, \& Ho, 2020). Similar investigations were also done in Africa, including Gambia (Bah, Fu, \& Ho, 2019), Cameroon (Tchuifon Tchuifon, Fu, \& Ho, 2017) and Ghana (Boamah \& Ho, 2018). A compared bibliometric study of Brunei (an Asian country) and Neotropical countries was also recently published (Ho et al., 2018). Other approaches 
have been used to evaluate country publication performance, for example, six publication indicators such as total, independent, collaboration, first-author, corresponding-author, and singleauthor publications (Ho \& Kahn, 2014); and citation indicators, for instance, total citations from Web of Science Core Collection since publication to the end of the most recent year (Wang, Fu, \& Ho, 2011; Chuang, Wang, \& Ho, 2011), citations in the most recent year only (Ho, 2012), and citations per publication ( Fu, Wang, \& Ho, 2012; Ho, 2018).

Located in Southeast Asia, Vietnam is the 15 th most populous country in the world, with a mean yearly per capita gross domestic product of \$ 8000 and a medium human development index of 0.69 ; despite widespread poverty, the country's economy has grown significantly in recent years (Fforde, 2019). The Vietnam State Science Committee was established in 1959 with social, applied and basic science branches. In the early 1970s, scientific research facilities were also established in Nghia Do to cover Mathematics, Physics, and Marine Studies (vast.ac.vn). The 1980s were marked by close work with the Soviet Union, followed in 1993 by an emphasis on using high technological research for socio-economic development and more recently by the formal establishment of the Vietnam Academy of Science and Technology (vast.ac.vn, chinhphu.vn).

A study done a decade ago found that Vietnamese researchers were active in fields of pure and applied mathematics, theoretical and applied physics, public health and infectious diseases (Nguyen \& Pham, 2011). A recent study reported that most Vietnam papers in the SCI are attributable to international collaboration, and that Vietnam is building up research capacity (Nguyen, Ho-Le, \& Le, 2017). The country also has a growing academic interest in eco-compensation (Yu et al., 2020) and has good citation rates for Mekong River research (Sui, Chen, Lu, \& Chen, 2015) and dengue research (Dwivedi, 2017), as well as patents for the printing industry, which show capacity for innovation (Kwon, Li, \& Sohn, 2019).
The aim of this study was to analyze publications by Vietnamese researchers, in all fields of science covered by the Science Citation Index Expanded (SCI-EXPANDED) from 1991 to 2018, and to compare Vietnam with other tropical countries.

\section{MATERIALS AND METHODS}

The data refer not only to tropical biology, but to all areas of science covered by the Science Citation Index Expanded (last updated October 03, 2019). We searched for "Vietnam" in the country field, 1991 to 2018 . The impact factors $\left(I F_{2018}\right)$, used to compare the impact of different document types, and of locally-lead versus foreign-lead projects, were extracted from the 2018 Journal Citation Reports (JCR).

The database uses the term "reprint author", but here we use "corresponding-author". Single authors are considered both first- and corresponding- authors in this study. In documents with several "corresponding-authors" we used the last "corresponding-author". We used three citation indicators. The first was the number of citations from the Web of Science Core Collection in a particular year, for instance, $C_{2018}$ means the number of citations in 2018 (for a justification, see Ho, 2012). The second was total citations from the Web of Science Core Collection since publication to the end of 2018 was recorded as $T C_{2018}$. The third was mean citations per publication $\left(C P P_{2018}=T C_{2018} / T P\right)$.

\section{RESULTS}

Results are presented below according to type of publication, language, impact, subject and collaboration. Note: Figures 4-7, and Tables 3-9, appear as supplementary files in Digital Appendix 1 (figures) and Digital Appendix 2 (tables).

Document type and language of publication: The index records 17 document types and 34790 publications from Vietnam for the 
period 1991-2018. The majority were articles (90\% of 34790 publications), followed distantly by meeting abstracts (5.4\%), proceedings papers $(3.8 \%)$, and reviews $(2.5 \%)$ (Table 1).

The maximal citations per publication value $\left(C P P_{2018}\right)$ was in reviews with 34 , which was 2.6 times the citation rate of common articles (Table 1). The mean number of authors per publication $(A P P)$ was 93 in data papers, 16 in articles and 9.2 in reviews (Table 1). Web of Science can classify a document in more than one type, for example, 1332 proceedings papers were also classified as articles, and thus the sum of percentages can be higher than $100 \%$. We chose only journal articles (31216 articles) for further analysis because they represented the majority of document types, as well as whole research ideas and results (Ho, Satoh, \& Lin, 2010).

Language of publication is one of the basic concerns in bibliometric studies of big data analysis (Wang \& Ho, 2011). Vietnam research was published in a total of 12 languages (Table 8 in Appendix 1), but $99 \%$ were in English
(31 017 articles), followed distantly by French (94; $0.30 \%$ ), Russian (64; $0.21 \%$ ), and German $(19 ; 0.061 \%)$. Other languages were Chinese (8; $0.026 \%)$, Japanese $(5 ; 0.016 \%)$, Czech (2; $0.0064 \%)$, and Dutch $(2 ; 0.0064 \%)$. One article was bilingual (English and French). Articles not in English had fewer citations, with $C P P_{2018}$ of 2.7 , versus a $C P P_{2018}$ of 13 for English.

Publication output and citation impact: The $C P P_{2018}$ increased more rapidly in the first year after publication. The initial value for citations per publication was 0.63 and reached a peak with $C P P_{2018}$ of 3.0 in the 2 nd year (Fig. 1, Table 9 in Appendix 1).

The annual publication output and mean $C P P_{2018}$ for the years 1991-2018 appear in Fig. 2; they have increased steadily from 119 articles in 1991 to 4992 articles in 2018; while the highest $C P P_{2018}$ was found in 2001 and 2004 with $C P P_{2018}$ of 31 for isolated articles produced by large international research projects.

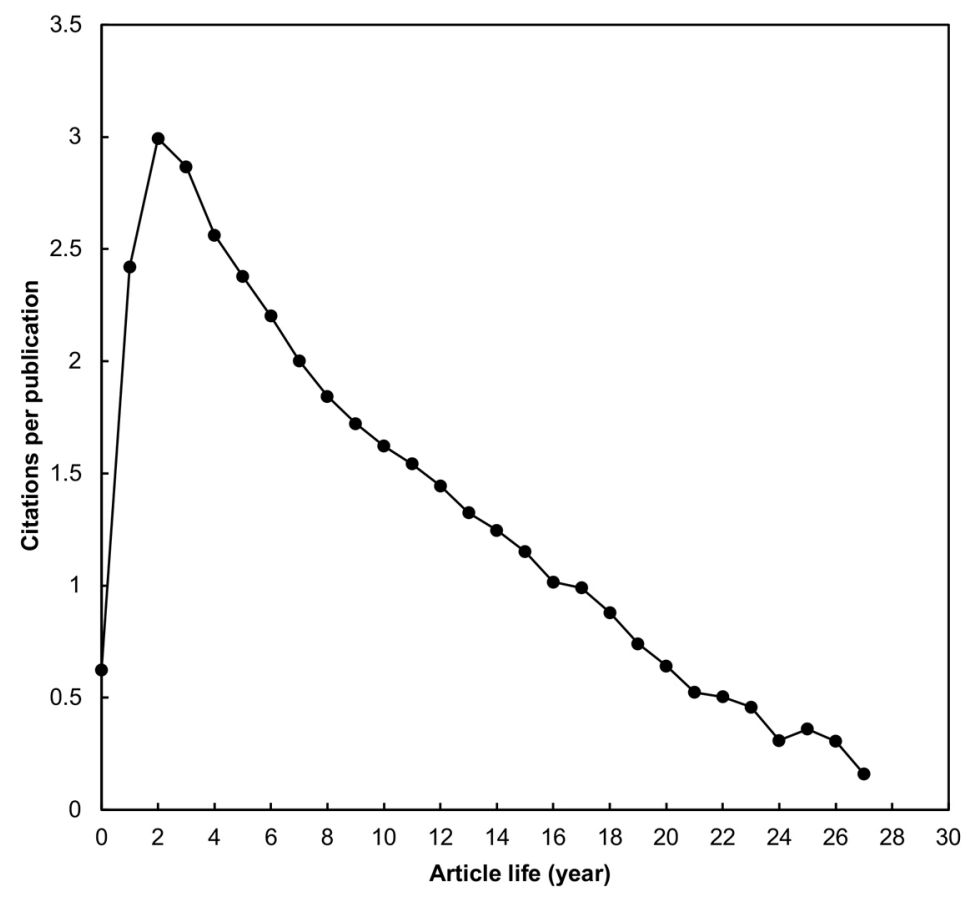

Fig. 1. Citation life span for Vietnam articles. 
TABLE 1

Characteristics of document type (percentage from a total of 34790 publications)

\begin{tabular}{lccccc}
\multicolumn{1}{c}{ Document type } & $\%$ & $A U$ & $A P P$ & $T C_{2018}$ & $C P P_{2018}$ \\
Article & 90 & 511277 & 16 & 402929 & 13 \\
Meeting abstract & 5.4 & 11659 & 6.2 & 198 & 0.11 \\
Proceedings paper & 3.8 & 6845 & 5.1 & 14221 & 11 \\
Review & 2.5 & 7932 & 9.2 & 28998 & 34 \\
Editorial material & 0.83 & 1579 & 5.5 & 3366 & 12 \\
Letter & 0.78 & 1813 & 6.7 & 1620 & 6.0 \\
Correction & 0.54 & 8698 & 46 & 155 & 0.82 \\
Note & 0.15 & 191 & 3.7 & 772 & 15 \\
Book chapter & 0.11 & 196 & 5.0 & 336 & 8.6 \\
News item & 0.069 & 94 & 3.9 & 58 & 2.4 \\
Retracted publication & 0.011 & 13 & 3.3 & 11 & 2.8 \\
Biographical-item & 0.0086 & 4 & 1.3 & 1 & 3.0 \\
Book review & 0.0086 & 3 & 1.0 & 20 & 0.33 \\
Data paper & 0.0086 & 279 & 93 & 7 & 6.7 \\
Reprint & 0.0086 & 23 & 4.0 & 0 & 2.3 \\
Retraction & 0.0086 & 12 & 1.0 & 5 & 0 \\
Addition correction & 0.0029 & 1 & & 5.0
\end{tabular}

$T P$ : number of publications; $A U$ : number of authors; $A P P:$ number of authors per publication; $T C_{2018}$ : the total number of citations from Web of Science Core Collection since publication to the end of 2018; $C P P_{2018}$ : number of citations $\left(T C_{2018}\right)$ per publication $(T P)$.

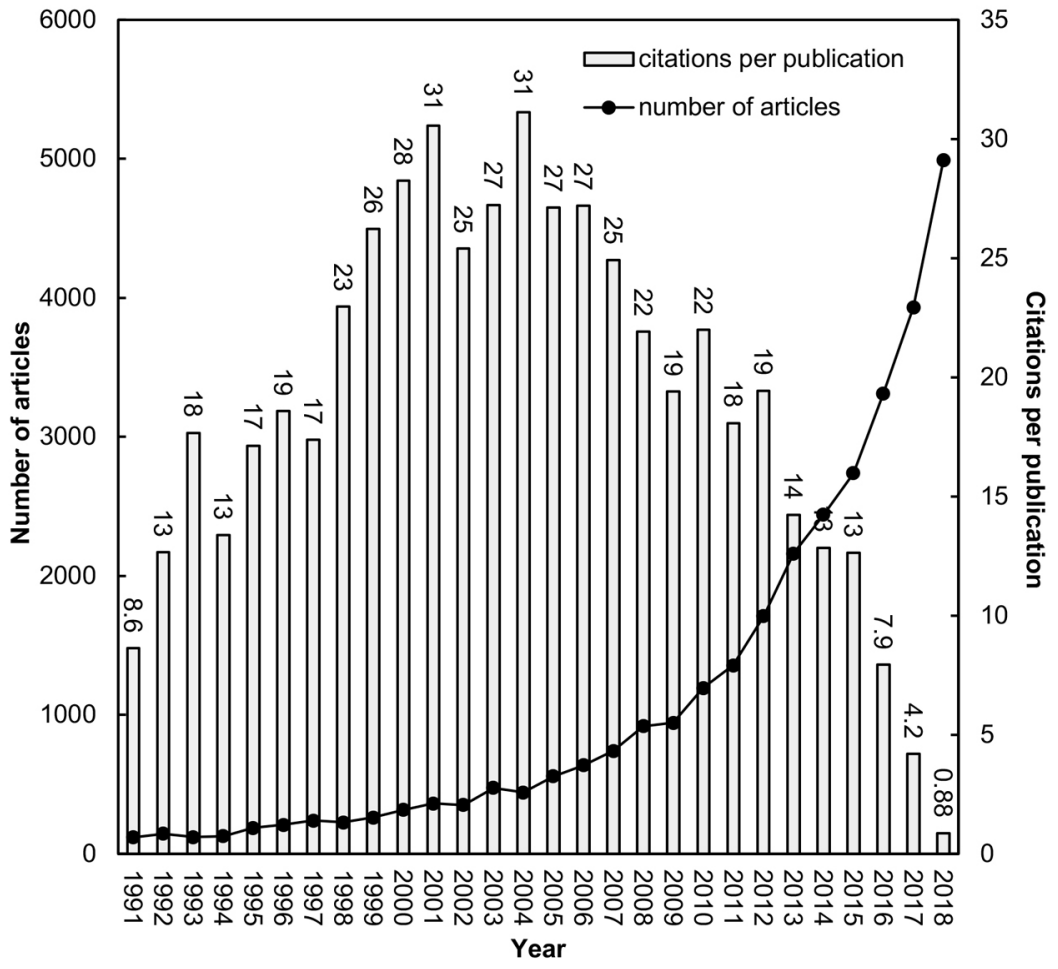

Fig. 2. Number of articles and citations per publication by year. 
Web of Science categories and journals: To assess development among research fields and their interactions, we used a relationship between the number of articles in each category and publication year (Ho, Satoh, \& Lin, 2010) (Fig. 4 in Appendix 2). The Vietnamese articles were published in 4783 journals among all 178 SCI-EXPANDED categories. The top ten productive Web of Science categories are listed in Table 2, and Fig. 5 in Appendix 2.

A total of 3129 articles (10\% of articles) were published in materials science-related categories including multidisciplinary materials science $(8.2 \%)$, composites materials science $(0.75 \%)$, coatings and films materials science $(0.46 \%)$, ceramics materials science $(0.31 \%)$, biomaterials materials science $(0.29 \%)$, characterization and testing materials science $(0.18$ $\%)$, paper and wood materials science $(0.10 \%)$, and textiles materials science $(0.048 \%)$. Similarly, a total of 2625 articles ( $8.4 \%$ of articles) were published in mathematics-related categories including mathematics $(7.5 \%)$, applied mathematics $(7.5 \%)$, and interdisciplinary applications mathematics (10\%).

The top 10 most productive journals are listed in Table 3 in Appendix 1 (Fig. 6 in Appendix 2). PLoS One $\left(I F_{2018}=2.776\right)$ in the category of multidisciplinary sciences, published the most articles with $393(1.3 \%$ of articles). Articles published in Physical Review $B$ and Journal of High Energy Physics had higher $C P P_{2018}$ of 18 and 17 respectively. In addition, articles published in Nature $\left(I F_{2018}=\right.$ 43.070) had a $C P P_{2018}$ of 1112 . These tend to be journals that publish well financed research from large international projects, often in the fields of physics and medicine articles (Long, Huang, \& Ho, 2014) with $T C_{2018}$ of 1000 or more Koboldt et al. (2012) with $T C_{2018}$ of 4 577; Bhatt et al. (2013) with $T C_{2018}$ of 2742 ; Altshuler et al. (2015) with $T C_{2018}$ of 2 385; Hammerman et al. (2012) with $T C_{2018}$ of 1 725; and Weinstein et al. (2014) with $T C_{2018}$ of 1 121. The large size of these projects is reflected in the number of authors, which range from 18 to 774. The journal with the highest $I F_{2018}$ (5.833) was the Journal of High Energy Physics with 155 articles, followed by Physical Review B $\left(I F_{2018}=3.736\right)$ with 148 articles, and PLoS One $\left(I F_{2018}=2.776\right)$ with 393 articles. Journals with the lower impact factors but still high in the rank included Zootaxa with an $I F_{2018}$ of 0.990 , and the Journal of the Korean Physical Society with an $I F_{2018}$ of 0.63 .

\section{Collaborative countries and institutes:} There were 24214 (78\% of 31216 ) internationally collaborative articles and 7002 (22 $\%$ of 31 216) Vietnam independent articles; of these 3104 (9.9\% of 31216 articles) nationally collaborative articles and 3898 (12 $\%)$ institutional independent articles. Overall, the internationally collaborative articles had a higher $C P P_{2018}$ of 15 , while Vietnam independent articles had a $C P P_{2018}$ of 5.6 (Fig. 3).

TABLE 2

Top 11 Web of Science categories with $T P>1000$ (Percentage from a total of 17720 articles)

\begin{tabular}{|c|c|c|}
\hline Web of Science categories & $\%$ & No. Journals \\
\hline Multidisciplinary Materials Science & 8.2 & 293 \\
\hline Mathematics & 7.5 & 313 \\
\hline Applied Mathematics & 7.5 & 254 \\
\hline Applied Physics & 5.8 & 148 \\
\hline Environmental Sciences & 4.8 & 250 \\
\hline Electrical and Electronic Engineering & 4.4 & 265 \\
\hline Condensed Matter Physics & 4.2 & 68 \\
\hline Physical Chemistry & 3.6 & 148 \\
\hline Infectious Diseases & 3.6 & 89 \\
\hline Plant Sciences & 3.6 & 228 \\
\hline Public, Environmental and Occupational Health & 3.6 & 185 \\
\hline
\end{tabular}




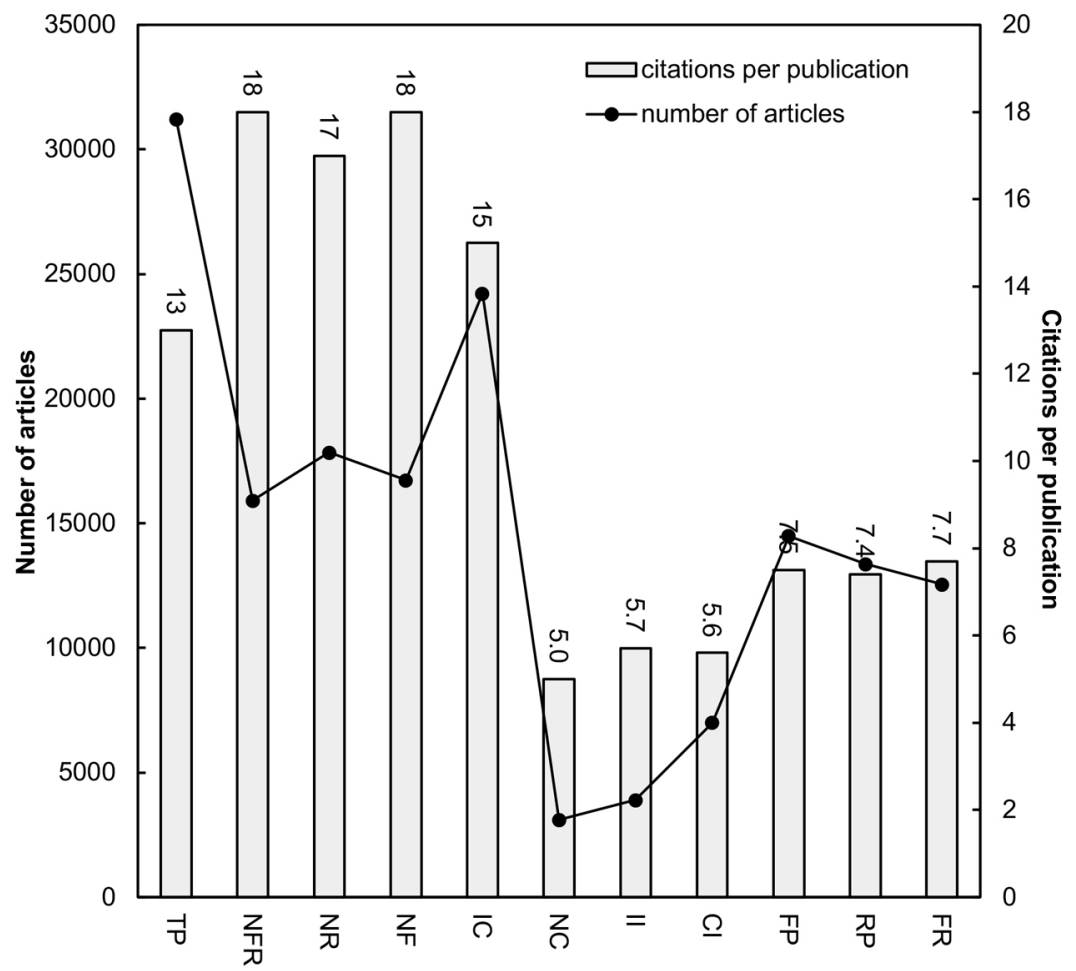

Fig. 3. Characteristics of publication type and their citations per publication. TP: total articles, NFR: both first and corresponding-authors are not from Vietnam, $N R$ : corresponding-author is not from Vietnam, $N F$ : first-author is not from Vietnam, $I C$ : internationally collaborative articles, $N C$ : nationally collaborative articles, $I I$ : institutional independent articles, $C I$ : Vietnam independent articles, $F P$ : first-author is from Vietnam, $R P$ : corresponding-author is from Vietnam, $F R$ : both first and corresponding-authors are from Vietnam.

Articles published with Vietnamese researchers as first- or corresponding-authors had lower $C P P_{2018}$ of 7.5 and 7.4, respectively (Fig. 3). Neither the first nor the corresponding-authors of the most cited articles are Vietnamese, with a mean of 18 citations per publication (Fig. 3).

The top ten most collaborative countries are listed in Table 4 in Appendix 1 (Fig. 7 in Appendix 2). Vietnamese researchers collaborated the most with the USA including 3949 internationally collaborative articles (13\% of articles). Nevertheless, Japan had the most first- and corresponding-author articles (7.1 and $7.6 \%$, respectively). Articles with Italy, the UK, and the Netherlands had higher citations per publication values (lower with South Korea and Japan).

A total of $3898(12 \%)$ articles were single institution articles $(I P)$ and $88 \%$ were inter-institutionally collaborative articles $(C P)$. Table 5 in Appendix 1 presents the 10 most productive institutions in Vietnam. The Vietnam Academy of Science and Technology ranked top in the all six publication indicators with $T P$ of 5673 articles (18\% of articles), $I P$ of 835 articles $(21 \%$ of 3898 institute independent articles), a $C P$ of 4838 articles (18\% of 27318 inter-institutionally collaborative articles), a FP of 2496 articles (8.0\% of 31216 first-author articles), a $R P$ of 2343 articles $(7.6 \%$ of 30911 corresponding-author articles), and an SP of 395 articles (20\% of 1951 single-author articles). The Oxford University Clinical Research Unit published 782 articles, therein three single-institute articles and two single-author articles had a $C P P_{2018}$ of 58 , the highest value. 
Table 6 in Appendix 1 presents the top 10 oversea institutions that collaborated with Vietnam in research publications with three publication indicators $T P, F P$, and $R P$, and citation indicator $C P P_{2018}$. Vietnam collaborated the most articles with University of Oxford in the UK, at 1151 articles. The Russian Academy of Sciences had 692 collaborative articles with Vietnam including 280 first-authors articles and 286 corresponding-author articles. Collaborative articles with Heidelberg University in Germany had the highest $C P P_{2018}$ (63), followed by University of Oxford in the UK with a $C P P_{2018}$ of 52 and the University of Edinburgh, also in the UK, with a $C P P_{2018}$ of 50.

Citation life cycles of the most frequently cited articles: A total of 446 articles had a $T C_{2018}$ of $100,52 \%$ with a first-author from the USA (17\%), the UK (12\%), France (6.3 $\%)$, Japan (6.1\%), Switzerland (5.8\%), and Netherlands (4.5\%), while $50 \%$ were published by a corresponding-author from the USA (19\%), the UK (13\%), France (7.2\%), Switzerland (5.8\%), and Japan (5.6\%). Table 7 in Appendix 1 shows the ten classic articles with a $T C_{2018}$ of 1000 or more (Long et al., 2014). Nine had first- and corresponding-authors from the USA, in the tenth, they were from the UK. Eight articles were published by a big group with 357 to 774 authors. Furthermore, the Vietnam independent article with the highest $T C_{2018}$ (238 total citations) was "Expanding applications of metal-organic frameworks: Zeolite imidazolate framework ZIF-8 as an efficient heterogeneous catalyst for the Knoevenagel reaction" (Tran, Le \& Phan, 2011) by U.P.N. Tran, K.K.A. Le, and N.T.S. Phan from the Department of Chemical Engineering at the HCMC University of Technology.

\section{DISCUSSION}

Vietnam published 17 document types, above other tropical countries, for example, 11 in Brunei (Ho et al., 2018), 12 in Gambia (Bah et al., 2019), 13 in Honduras (Monge-Nájera \&
Ho, 2017b), and 15 in Panama (Monge-Nájera \& Ho, 2015).

Vietnam was colonized by France and for many years French was a second language in the country, but its publications in this database are $99 \%$ in English, closer to countries like Gambia (Bah et al., 2019), Ghana (Boamah \& Ho, 2018), and Brunei (Ho et al., 2018) which were colonized by the British. A probable reason is that journals covered by this particular index publish mostly in English. Other trends may occur in journals that publish in French or Vietnamese, but these are not covered by the index, even if they are important for the local development of research in Vietnam. In fact, the Science Citation Index Expanded is far from giving a representative view of science in Vietnam, because $95 \%$ of all articles are published in Vietnamese and not covered by the index (Hien, 2010).

The increase in the number of publications, in all fields of science, is a general trend of tropical countries in the last decade, the same trend has been found in Asia (Ho et al., 2018), Africa (Boamah \& Ho, 2018; Bah et al., 2019), and Latin America (Monge-Nájera \& Ho, 2018; Calahorrano et al., 2020).

Vietnamese research published in collaboration with other countries was more cited in this database $\left(C P P_{2018}\right)$ than local articles. Similarly, articles published by first-authors or corresponding-authors from Vietnam also had lower $C P P_{2018}$ values. For the 446 highly cited articles $\left(T C_{2018} 100\right), 53 \%$ had a first-author from the USA, the UK, France, Japan, Switzerland, or the Netherlands, while $50 \%$ were published by a corresponding-author from the USA, the UK, France, Switzerland, or Japan. International collaboration with developed countries produced higher citation rates. The USA contributed the most citations to Vietnam publications. The USA, Japan, South Korea, and France were the most frequent research partners. Collaborative articles with Italy, the UK, and Netherlands had higher citations. These patterns can be also found in other tropical countries (Monge-Nájera \& Ho, 2017a; 2017b; 2017c; Tchuifon Tchuifon et al., 2017; 
Ho et al., 2018; Boamah \& Ho, 2018; Bah et al., 2019; Calahorrano et al., 2020).

Vietnam published more articles than other tropical countries. However, its independent articles had lower citation rates $\left(C P P_{2018}\right.$ 5.6) than tropical countries in Latin America such as Guatemala with a $C P P_{2018}$ of 13 (MongeNájera \& Ho, 2018), Ecuador (8.5) (Calahorrano et al., 2020), Honduras (7.5) (Monge-Nájera \& Ho, 2017b), Nicaragua (6.4) (Monge-Nájera \& Ho, 2017a), El Salvador (5.9) (MongeNájera \& Ho, 2017c), and Ghana (6.4) in Africa (Boamah \& Ho, 2018) and Brunei (7.9) in Asia (Ho et al., 2018).

Vietnam publications were dominated by materials science, which is different from other tropical countries, for example, ecology in Brunei (Ho et al., 2018), Ecuador (Calahorrano et al., 2020), and Panama (Monge-Nájera \& Ho, 2015); public, environmental and occupational health in Cameroon (Tchuifon et al., 2017), El Salvador, Gambia (Bah, Fu, \& Ho, 2019), Ghana (Boamah \& Ho, 2018), Guatemala (Monge-Nájera \& Ho, 2018), Honduras (Monge-Nájera \& Ho, 2017b), and Nicaragua (Monge-Nájera \& Ho, 2017a).

Tropical medicine, plant sciences, immunology, infectious diseases, and nutrition and dietetics also dominated research in tropical countries (Tchuifon et al., 2017; Bah et al., 2019; Boamah \& Ho, 2018; Monge-Nájera \& Ho, 2018; Monge-Nájera \& Ho, 2017b). However, Costa Rica published the most articles in biology (Monge-Nájera \& Ho, 2012).

The reason for the importance of materials science research in Vietnam is that the subject was included as a priority by the government (Zink, 2009).

In conclusion, the tropical countries of Latin America, Africa, and Asia studied have some similarities in the importance of applied research subjects, and their dependence on foreign initiatives, but there are also crucial differences. Although science in Vietnam is developing and shows a positive trend in number of papers and citations, most of the impact found in this study results from minor participation of Vietnamese authors in large international projects. This important conclusion that we obtain from our data sadly matches the findings and call made over a decade ago by Hien, who stated that Vietnam depended too much on foreign authors, and called for more multidisciplinary work and internationally-recognized standards (Hien, 2010). For a more robust development of local science, the country should significantly enhance collaboration among Vietnamese institutes in order to lessen its dependence on overseas projects, even if at the beginning this causes a fall in the impact of their work as measured by this particular database.

Ethical statement: authors declare that they all agree with this publication and made significant contributions; that there is no conflict of interest of any kind; and that we followed all pertinent ethical and legal procedures and requirements. All financial sources are fully and clearly stated in the acknowledgements section. A signed document has been filed in the journal archives.

\section{ACKNOWLEDGMENTS}

We are grateful to Carolina Seas for her valuable help with the manuscript, and we thank three anonymous reviewers for careful and useful suggestions to improve the manuscript.

\section{RESUMEN}

Bibliometría de las publicaciones de Vietnam en el Science Citation Index: tendencias generales y comparación con otros países tropicales. Introducción: La economía de Vietnam, un país tropical muy poblado con un producto interno bruto per cápita de $\$ 8000$, está creciendo rápidamente, pero hay pocos estudios recientes y de enfoque general sobre su productividad científica y cómo se compara con la de otros países tropicales. Objetivo: identificar tendencias en la ciencia vietnamita y compararlas con las tendencias en otros países tropicales. Métodos: extrajimos datos sobre artículos científicos, en todas las disciplinas que tenían a Vietnam como "país" en el Science Citation Index Expanded para el período 1991 a 2018, centrándonos en el tipo de publicación, idioma, tema, autoría, colaboración y citas. Resultados: Vietnam publica más tipos de documentos que otros países tropicales, 
y los de esta base de datos en particular están principalmente en inglés, aunque la mayoría de la ciencia vietnamita se publica en vietnamita y no está cubierta por el índice. Las categorías principales fueron ciencia de materiales (estudios multidisciplinarios), matemáticas y matemáticas aplicadas. La mayor parte de la colaboración se realizó con EE. UU., Japón, Corea del Sur y Francia. La Academia de Ciencia y Tecnología de Vietnam publicó una proporción importante de estos artículos, y la colaboración extranjera más frecuente fue con la Universidad de Oxford. Conclusión: los países tropicales de América Latina, África y Asia estudiados en nuestro proyecto tienen tanto similitudes como diferencias importantes con Vietnam. La ciencia en Vietnam está en una etapa de crecimiento y convendría estudiar los artículos que se publican en vietnamita, los cuales representan la amplia mayoría de la ciencia del país, pero no se incluyen en esta base de datos.

Palabras clave: productividad científica; colaboración científica; Asia; ciencia tropical.

\section{REFERENCES}

Altshuler, D.M., Durbin, R.M., Abecasis, G.R., Bentley, D.R., Chakravarti, A., Clark, A.G., ... Abecasis, G.R. (2015). A global reference for human genetic variation. Nature, 526(7571), 68-74.

Bah, K., Fu, H.Z., \& Ho, Y.S. (2019). Gambia publications in the Science Citation Index Expanded: Bibliometrics of institutions and subjects. Revista de Biología Tropical, 67(3), 490-500.

Bhatt, S., Gething, P.W., Brady, O.J., Messina, J.P., Farlow, A.W., Moyes, C.L., ... Hay, S.I. (2013). The global distribution and burden of dengue. Nature, 496(7446), 504-507.

Boamah, P.O., \& Ho, Y.S. (2018). Bibliometric analysis of Ghana publications in the Science Citation Index Expanded. Revista de Biología Tropical, 66(1), 106-121.

Calahorrano, L., Monge-Nájera, J., Wang, M.H., \& Ho, Y.S. (2020). Ecuador publications in the Science Citation Index Expanded: institutions, subjects, citation and collaboration patterns. Revista de Biología Tropical, 68(1), 98-107.

Chuang, K.Y., Wang, M.H., \& Ho, Y.S. (2011). Highimpact papers presented in the subject category of water resources in the Essential Science Indicators database of the Institute for Scientific Information. Scientometrics, 87(3), 551-562.

Dwivedi, S. (2017). Dengue research: Three dimensional bibliometric study of the global research output during 1989-2015. DESIDOC Journal of Library, \& Information Technology, 37(3), 180-185.
Fforde, A. (2019). From plan to market: The economic transition in Vietnam. Abingdon-on-Thames, England: Routledge.

Fu, H.Z., Wang, M.H., \& Ho, Y.S. (2012). The most frequently cited adsorption research articles in the Science Citation Index (Expanded). Journal of Colloid and Interface Science, 379(1), 148-156.

Hammerman, P.S., Lawrence, M.S., Stojanov, P., Lander, E.S., Gabriel, S., Getz, G., ... Meyerson, M. (2012). Comprehensive genomic characterization of squamous cell lung cancers. Nature, 489(7417), 519-525.

Hien, P.D. (2010). A comparative study of research capabilities of East Asian countries and implications for Vietnam. Higher Education, 60(6), 615-625.

Ho, Y.S. (2012). Top-cited articles in chemical engineering in Science Citation Index Expanded: A bibliometric analysis. Chinese Journal of Chemical Engineering, 20(3), 478-488.

Ho, Y.S. (2018). Classic papers published by Taiwanese scientists in the science citation index expanded: A bibliometric study. COLLNET Journal of Scientometrics and Information Management, 12(1), 83-95.

Ho, Y.S., \& Kahn, M. (2014). A bibliometric study of highly cited reviews in the Science Citation Index Expanded $^{\mathrm{TM}}$. Journal of the Association for Information Science and Technology, 65(2), 372-385.

Ho, Y.S., Lim, L.B.L., \& Monge-Nájera, J. (2018). Brunei publications in the Science Citation Index Expanded (1973-2016): Bibliometrics and comparison with other tropical countries. Revista de Biología Tropical, 66(3), 1090-1100.

Ho, Y.S., Satoh, H., \& Lin, S.Y. (2010). Japanese lung cancer research trends and performance in Science Citation Index. Internal Medicine, 49(20), 2219-2228.

Koboldt, D.C., Fulton, R.S., McLellan, M.D., Schmidt, H., Kalicki-Veizer, J., McMichael, J.F., ... Palchik, J.D. (2012). Comprehensive molecular portraits of human breast tumors. Nature, 490(7418), 61-70.

Kwon, D.S., Li, D., \& Sohn, S.Y. (2019). Identifying innovation in socialist countries through patent analysis focused on Cuba and Vietnam. World Patent Information, 59, 101898.

Long, X., Huang, J.Z., \& Ho, Y.S. (2014). A historical review of classic articles in surgery field. American Journal of Surgery, 208(5), 841-849.

Monge-Nájera, J., \& Ho, Y.S. (2012). Costa Rica publications in the Science Citation Index Expanded: A bibliometric analysis for 1981-2010. Revista de Biología Tropical, 60(4), 1649-1661.

Monge-Nájera, J., \& Ho, Y.S. (2015). Bibliometric of Panama publications in the Science Citation Index 
Expanded: Publication type, language, fields, authors and institutions. Revista de Biología Tropical, 63(4), 1255-1266.

Monge-Nájera, J., \& Ho, Y.S. (2017a). Bibliometrics of Nicaraguan publications in the Science Citation Index Expanded. Revista de Biología Tropical, 65(2), 643-655.

Monge-Nájera, J., \& Ho, Y.S. (2017b). Honduras publications in the Science Citation Index Expanded: institutions, fields and authors. Revista de Biología Tropical, 65(2), 657-668.

Monge-Nájera, J., \& Ho, Y.S. (2017c). El Salvador publications in the Science Citation Index Expanded: subjects, authorship, collaboration and citation patterns. Revista de Biología Tropical, 65(4), 1428-1436.

Monge-Nájera, J., \& Ho, Y.S. (2018). Guatemala articles in the Science Citation Index Expanded: bibliometry of subjects, collaboration, institutions and authors. Revista de Biología Tropical, 66(1), 312-320.

Nguyen, T.V., \& Pham, L.T. (2011). Scientific output and its relationship to knowledge economy: An analysis of ASEAN countries. Scientometrics, 89(1), 107-117.

Nguyen, T.V., Ho-Le, T.P., \& Le, U.V. (2017). International collaboration in scientific research in Vietnam: an analysis of patterns and impact. Scientometrics, $110(2), 1035-1051$.

Sui, X.Y., Chen, Y.X., Lu, Z., \& Chen, Y.F. (2015). A bibliometric analysis of research papers related to the Mekong River. Scientometrics, 105(1), 419-434.

Tchuifon Tchuifon, D.R., Fu, H.Z., \& Ho, Y.S. (2017). Cameroon publications in the Science Citation Index Expanded: Bibliometric analysis. Revista de Biologia Tropical, 65(4), 1582-1591.

Tran, U.P.N., Le, K.K.A., \& Phan, N.T.S. (2011). Expanding applications of metal-organic frameworks: Zeolite imidazolate framework ZIF-8 as an efficient heterogeneous catalyst for the Knoevenagel reaction. ACS Catalysis, 1(2), 120-127.

Vos, T., Allen, C., Arora, M., Barber, R.M., Bhutta, Z.A., Brown, A., ... Murray, C.J.L. (2016). Global regional and national incidence prevalence and years lived with disability for 310 diseases and injuries 19902015: a systematic analysis for the Global Burden of Disease Study 2015. The Lancet, 388(10053), 1545-1602.

Vos, T., Barber, R.M., Bell, B., Bertozzi-Villa, A., Biryukov, S., Bolliger, I., ... Murray, C.J.L. (2016). Global, regional, and national incidence, prevalence, and years lived with disability for 301 acute and chronic diseases and injuries in 188 countries, 1990-2013: a systematic analysis for the Global Burden of Disease Study 2013. The Lancet, 386(9995), 743-800.

Wang, M.H., Fu, H.Z., \& Ho, Y.S. (2011). Comparison of universities' scientific performance using bibliometric indicators. Malaysian Journal of Library, \& Information Science, 16(2), 1-19.

Wang, M.H., \& Ho, Y.S. (2011). Research articles and publication trends in environmental sciences from 1998 to 2009. Archives of Environmental Science, $5,1-10$.

Weinstein, J.N., Akbani, R., Broom, B.M., Wang, W.Y., Verhaak, R.G.W., McConkey, D., \& Eley, G. (2014). Comprehensive molecular characterization of urothelial bladder carcinoma. Nature, 507(7492), 315-322.

Yu, H.J., Xie, W., Yang, L., Du, A.S., Almeida, C.M.V.B., \& Wang, Y.T. (2020). From payments for ecosystem services to eco-compensation: Conceptual change or paradigm shift? Science of the Total Environment, 700, UNSP 134627.

Zink, E. (2009). Science in Vietnam. An assessment of IFS grants, young scientists, and the research environment. Stockholm, Sweden: International Foundation for Science.

See Digital Appendix at: / Ver Apéndice digital en: revistas.ucr.ac.cr 